\title{
Target and distractor processing at several retinal locations
}

\author{
PAULA GOOLKASIAN \\ The University of North Carolina at Charlotte, Charlotte, North Carolina
}

\begin{abstract}
This research investigated the allocation of attention to target and distractor stimuli presented at varied retinal locations. Previous studies found that the spatial distribution of target and distractor stimuli affected the amount of interference obtained in Stroop-like tasks. This study tested whether the spatial distribution effect was affected by the use of a moving target and by the presentation of a distractor in advance of the target. The results extended the spatial distribution effect to a task involving apparent motion and showed that the advance presentation of a distractor at varied stimulus onset asynchronies did not influence the phenomenon under study.
\end{abstract}

This research investigated the processing of target and distractor stimuli presented at varied retinal locations. Studies have found that spatial distribution of target and distractor stimuli affects the amount of interference obtained in Stroop-like tasks. A Stroop-like task involves multidimensional stimuli with varied target and distractor compatibility. Typically, when Stroop stimuli (Stroop, 1935) are presented, compatible distractors speed up target responding and incompatible distractors lengthen it. There is evidence, however, that directing attention toward a target that has been presented at some distance from a foveally presented distractor reduces or eliminates the Stroop interference effect (Goolkasian, 1981; Humphreys, 1981; Kahneman \& Henik, 1981).

The present study extended this finding by investigating the effect of a distractor on perception of moving and stationary targets. The spatial distribution effect has been obtained with a variety of tasks, but they were stationary tasks involving form and color detection. It was of interest to investigate moving targets because people's use of peripheral vision in routine tasks (e.g., walking and driving) often involves moving rather than stationary targets.

In this study, motion was created by a rectangular shape $\left(1.1^{\circ} \times 1.2^{\circ}\right)$ presented in two frames serially flashed on a black-and-white screen. The target appeared to move over $3.4^{\circ}$ and was considered long-range motion (Anstis, 1980). Dick, Ullman, and Sagi (1987) recently demonstrated that apparent motion can be used to study perception of the direction of motion in the visual field. Detection of the direction of a moving target in the present study was compared with detection of the orientation of a stationary target. The stationary target was the letter $\mathrm{C}\left(3.21^{\circ}\right.$

This work was supported in part by funds from the Foundation of the University of North Carolina at Charlotte and from the State of North Carolina. Requests for reprints should be sent to Paula Goolkasian, Department of Psychology, University of North Carolina at Charlotte, Charlotte, NC 28223. $\left.\times 2.63^{\circ}\right)$ oriented in different directions. Subjects indicated the target direction with a keypress.

As in a previous study (Goolkasian, 1981), a word distractor was presented at fixation, and it was one of three types. Compatible words spelled out the target response, incompatible words spelled out a different response, and neutral distractors were a string of Xs that provided no information about the target direction. A comparison of compatible and neutral distractors would reveal facilitation effects, whereas interference effects would be measured by comparing incompatible and neutral distractors.

In addition to task comparisons, the presentation of the target and distractor were varied in four stimulus onset asynchronies (SOAs) to determine the effect of the advance presentation of the distractor on target processing. If the spatial distribution effect occurs because target processing is more demanding in the periphery than it is in the fovea, then presenting the word distractor in advance of the target would have an influence on the spatial distribution effect.

Reaction times were measured in response to moving and stationary targets presented directly above or $10^{\circ}$ to the right or the left of fixation. The target appeared to move, or was oriented, to either the right or the left. Response latencies were measured from the target onset, and responses indicated the direction of the apparent movement or the orientation of the stationary target. Target and distractor stimuli were presented briefly $(100 \mathrm{msec})$ to preclude eye movements in the direction of the peripheral targets. Average latency for initiation of a saccade is reported to be $200 \mathrm{msec}$ (Alpern, 1972), so it was assumed that eye movements did not occur prior to a target response.

On every trial, a compatible, incompatible, or neutral distractor appeared at fixation. Distractors either preceded the target by 500,333 , or $166 \mathrm{msec}$ or appeared simultaneously with the target. Distractor onset was varied to examine its influence on the processing of moving and stationary targets. 


\section{METHOD}

\section{Stimuli and Apparatus}

The target and distractor stimuli appeared on a 20-in. black-and-white monitor controlled by an Apple II+ microcomputer. The apparent movement of the target was created by flashing a cursor consecutively for $50 \mathrm{msec}$ in two separate screen positions. There was no interstimulus interval between the frames. The target appeared to move across the screen $(3 \mathrm{~cm})$ in either a right or a left direction. The stationary target consisted of asterisks placed within a $3 \times 2$ matrix to form a letter $\mathrm{C}$ with the opening to the right or left. With the subject $50 \mathrm{~cm}$ from the screen, the target locations were foveal (the target appeared in the row above the distractor $2 \mathrm{~cm}$ above the fixation cross) or peripheral $\left(10^{\circ}\right.$ to the right or left of the foveal location).

The distractors were the words "right" or "left" or a string of 4 Xs written to the center of the screen at the fixation point. Each letter was $1.15^{\circ}$ high, and the widths of the stimuli were $4.1^{\circ}, 3.4^{\circ}$, and $3.4^{\circ}$, respectively. The distractors were uppercase characters from the Apple ASCII character set.

Real time control of the stimulus presentation rates and the response timing were provided by a peripheral clock (Digitry Cognitive Testing Station). Accuracy of the clock is reported by the manufacturer to be $0.1 \mathrm{msec}$. A two-switch response box that interfaced with the Apple II was used to record the keypress responses. A Pascal program controlled the presentation of the stimuli and collected the subjects' responses.

\section{Procedure and Subjects}

On each trial, a fixation cross appeared in the center of the screen for $500 \mathrm{msec}$. The distractor and target followed with varied SOA intervals. The distractor appeared $500,333,166$, or $0 \mathrm{msec}$ in advance of the target.

The subjects participated individually in 50 -min sessions. They were instructed to fixate on the center cross, ignore the distractor, and indicate the direction of the target motion or the orientation of the letter as quickly as possible by pressing one of two microswitches positioned under the index fingers of both hands. The subjects were given $2 \mathrm{sec}$ to respond (responses made after $2 \mathrm{sec}$ were not scored). A chinrest was used at all times to stabilize head movements. Before experimental participation, the subjects were informed about the general nature of the task and familiarized with the stimulus set by going through 30 practice trials.

Stationary and moving targets were manipulated as a between-subject factor. Thus, there were two groups of subjects randomly assigned to tasks. SOA, distractor type, and spatial location of the target (foveal vs. peripheral) were manipulated as within-subject variables. The experimental session consisted of 480 trials, 20 at each of the SOA $\times$ distractor type $\times$ retinal location conditions. For certain conditions, target direction and target location to the right or left of the fixation point were balanced within the 20 trials. Trials from each of the 24 experimental conditions were randomly presented, and presentation orders were randomized for each subject.

Fifty men and women students at the University of North Carolina at Charlotte participated as subjects for extra credit points in their psychology lab course. They had $20 / 20$ or corrected $20 / 20$ vision and no history of visual abnormalities. The subjects were randomly divided to participate in the task with either the stationary or the moving target. To screen subjects and to prevent the participation of a subject with an undiagnosed visual problem, subjects had to respond correctly to $75 \%$ of the practice trials to continue with the experiment. No subjects were removed for failure to reach this criterion.

\section{RESULTS}

Table 1 presents mean correct response latencies computed across the 20 items for each subject within each of the experimental conditions. A $2 \times 4 \times 2 \times 3$ analysis of variance was used on these data to test for the main effects and interaction effects of the four variables of interest. Task was the only between-subject factor in the
Table 1

Mean Reaction Times (in msec) for the Experimental Conditions

\begin{tabular}{rccc}
\hline \multirow{2}{*}{$\begin{array}{c}\text { SOA } \\
\text { (in msec) }\end{array}$} & Compatible & Neutral & Incompatible \\
\cline { 2 - 4 } 5 & Apparent Motion Target, Foveal Location \\
500 & 443 & 444 & 456 \\
333 & 434 & 452 & 452 \\
166 & 461 & 462 & 469 \\
0 & 475 & 483 & 499 \\
& Apparent Motion Target, Peripheral Location \\
500 & 499 & 498 & 493 \\
333 & 489 & 492 & 490 \\
166 & 504 & 509 & 510 \\
0 & 538 & 523 & 554 \\
& & \\
500 & Stationary Target, Foveal Location & \\
333 & 405 & 426 & 421 \\
166 & 420 & 414 & 430 \\
0 & 438 & 440 & 453 \\
& 472 & 475 & 477 \\
500 & Stationary Target, Peripheral Location \\
333 & 451 & 453 & 448 \\
166 & 442 & 448 & 446 \\
0 & 472 & 465 & 472 \\
& 500 & 503 & 507 \\
\hline
\end{tabular}

Note-SOA $=$ stimulus onset asynchrony.

analysis. Error rates for each subject in each condition were also recorded.

As expected, there was an interaction of target location $\times$ distractor type $[F(2,96)=3.78, p=.02]$, and this effect was consistent with the spatial distractor effect identified in previous studies. As can be seen in Figure 1, incompatible distractors interfered with target responding only when targets appeared in the foveal location. When attention was directed to peripheral targets, distractor type did not influence target responding. This effect, however, was not found to vary with task. There was neither a task $\times$ target location $\times$ distractor type interaction $(F<1)$ nor an interaction of task $\times$ distractor type $(F<1)$. The distribution of attention across target and distractor stimuli was similar whether moving or stationary targets were used.

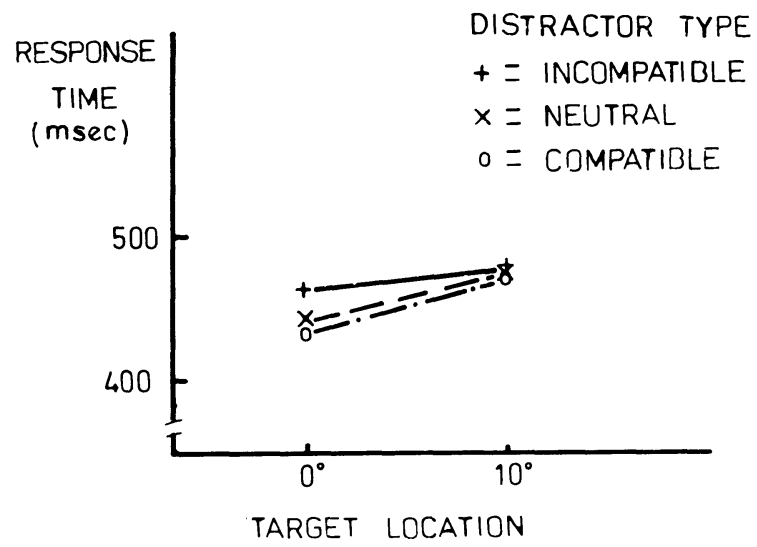

Figure 1. Target location $\times$ distractor type interaction. 


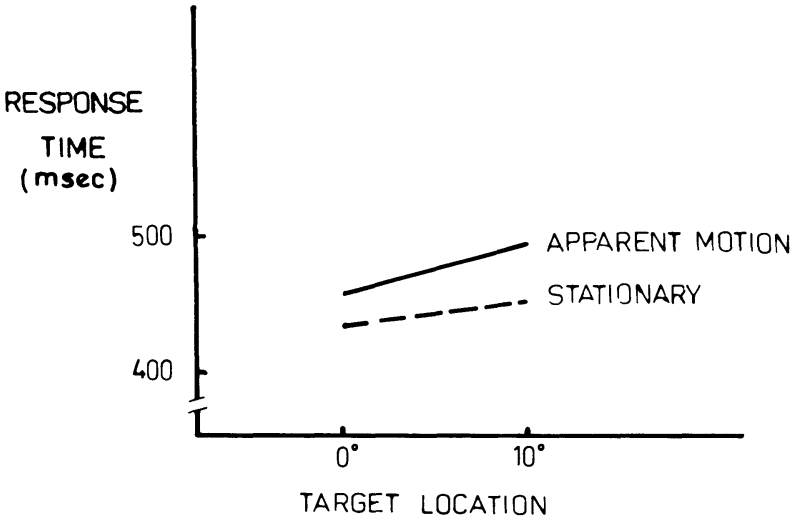

Figure 2. Task $\times$ target location interaction.

Task was found to interact with target location $[F(1,48)$ $=8.13, p=.006]$. Figure 2 presents this interaction. Although response latencies were longer for both kinds of targets in a peripheral location, the effect was more pronounced for moving targets. Contrary to expectations, processing the direction of apparent movement showed more change with retinal eccentricity than did the processing of stationary targets. However, even though response latencies from Figure 2 appeared to be slower for moving targets than for stationary targets, the main effect of task failed to reach significance $[F(1,48)=2.73$, $p<.10]$.

Targets presented in the foveal location were responded to more quickly than targets appearing in the peripheral location $[F(1,48)=111.41, p<.001]$, and there was a significant main effect of distractor type $[F(2,96)=$ $8.40, p<.001]$.

Also of importance to this study was the effect of SOA. The distractor's appearance 500 or $333 \mathrm{msec}$ in advance of the target resulted in quicker responding than in the other SOA intervals $[F(3,144)=153.39, p<.001]$. Average response times for the four SOA intervals, from longest to shortest, are as follows: 453, 451, 471, and $501 \mathrm{msec}$. Presentation of the distractor immediately before or simultaneously with the target interrupted target latencies. However, with the exception of a marginally significant effect of SOA $\times$ task $[F(3,144)=2.57$, $p<.06$ ], SOA was not found to interact with any of the variables of interest. The interaction of SOA $\times$ task occurred because processing stationary targets was more affected by SOA than was processing of moving targets.
The interaction of SOA $\times$ location $\times$ distractor type was not found $(F<1)$, nor was the interaction of SOA $\times$ distractor type $\times$ task $[F(6,288)=1.72, p<.11]$. The $F$ values for the other nonsignificant effects are as follows: SOA $\times$ distractor type $[F(6,288)=1.03]$, SOA $\times$ task $\times$ target location $(F<1)$, SOA $\times$ location $[F(3,144)=1.51, p=.231]$, and SOA $\times$ location $\times$ distractor type $\times$ task $[F(6,288)=1.14, p=.336]$.

\section{DISCUSSION}

The absence of any interactions with SOA suggests that presentation of the distractor in advance of the target did not have any influence on the spatial distribution effect. These data rule out the hypothesis that the locus of the effect is the lack of spare processing capacity to devote to the distractor. Even when the distractor appears in advance of the target, and it does not compete for scarce processing capacity, the spatial location of the target determines the extent of distractor processing. It appears as though stimulus processing is a spatially restricted phenomenon that is unaffected by the advance presentation of the distractor or by a change in the nature of the task.

An analysis of the error rates shows that subjects made an average of $3 \%$ errors in responding to foveal targets and $7 \%$ errors when responding to peripheral targets. However, task, SOA, and distractor type did not have any systematic effects on the error rate. The error rate data, together with the reaction time data, show that processing peripheral targets was more difficult than processing foveally placed targets. The effect is consistent across tasks and SOA level. However, there was no evidence that subjects traded speed for accuracy in performing this task.

In summary, the interaction of distractor type $\times$ target location replicates earlier findings of a spatial distractor effect, and demonstrates that the phenomenon occurs with both moving and stationary targets.

\section{REFERENCES}

AlPERN, M. (1972). Eye movements. In D. Jameson \& L. M. Hurvich (Eds.), Handbook of sensory physiology (Vol. 7). Berlin: Springer-Verlag.

ANSTIS, S. M. (1980). The perception of apparent movement. Philosophical Translation of the Royal Society of London B, 290, 153-168.

Dick, M., Ullman, S., \& SAGI, D. (1987). Parallel and serial processes in motion detection. Science, 237, 400-402.

Goolkasian, P. (1981). Retinal location and its effect on the processing of target and distractor information. Journal of Experimental Psychology: Human Perception \& Performance, 7, 1247-1257.

HuMPHREYS, G. W. (1981). On varying the span of visual attention: Evidence for two modes of spatial attention. Quarterly Journal of Experimental Psychology, 33A, 17-31.

Kahneman, D., \& Henik, A. (1981). Perceptual organization and attention. In M. Kubovy \& J. R. Pomerantz (Eds.), Perceptual organization. Hillsdale, NJ: Erlbaum.

STROOP, J. R. (1935). Studies of interference in serial verbal reaction. Journal of Experimental Psychology, 18, 643-662.

(Manuscript received September 22, 1988.) 